\title{
Grain size effect on radiation tolerance of nanocrystalline Mo
}

\author{
G. M. Cheng ${ }^{\mathrm{a}}$, W. Z. Xu' ${ }^{\mathrm{a}}$, Y. Q. Wang ${ }^{\mathrm{b}}$, A. Misra ${ }^{\mathrm{c}}$, Y. T. Zhu ${ }^{\mathrm{a}, *}$
}

${ }^{a}$ Department of Materials Science and Engineering, North Carolina State University, Raleigh, NC 27695, USA

${ }^{\mathbf{b}}$ Materials Science and Technology Division, Los Alamos National Laboratory, Los Alamos, NM 87545, USA

${ }^{\mathbf{c}}$ Department of Materials Science and Engineering, University of Michigan, Ann Arbor, MI 48109, USA

\begin{abstract}
We report a significant grain size effect on radiation tolerance of nanocrystalline Mo under He ion irradiation. Irradiation-induced dislocation loops mainly contribute to the irradiation-induced hardening of Mo films with grain size of $>90 \mathrm{~nm}$, while few such loops in those with grain size of $<90 \mathrm{~nm}$. The hardness increment after irradiation decreases with decreasing the grain size, and approaches zero at the grain size of $25 \mathrm{~nm}$. Also, the size and the density of irradiation-induced He bubbles decrease as the grain size decreases. This observation provides direct evidence that nanocrystalline body-centeredcubic metals have greater radiation tolerance than their ultra-fine-grained or coarsegrained counterparts.
\end{abstract}

Keywords: Radiation damage; Body-centered cubic (bcc); Nanocrystalline; Grain size effect; Magnetron sputtering

*Corresponding author. e-mail: ytzhu@ncsu.edu. 
Radiation damage is one of the critical issues for developing advanced materials used in next generation nuclear plants [1-8] and spacecrafts [9]. Hardening, swelling, embrittlement and creep are some of the critical issues associated with radiation damage. Irradiation can induce interstitials, vacancies or He bubbles in microstructure, which will further agglomerate to form loops, interstitial or vacancy clusters and voids in materials $[10,11]$. Formation of voids will lead to swelling and embrittlement, which are the main cause of material failure under irradiation environment [12]. Therefore, how to control the generation of irradiation-induced defects and mitigate the negative effects of $\mathrm{He}$ bubbles is the key to design advanced radiation tolerant materials with a balance of mechanical and thermal properties $[2,13]$.

Body-centered cubic (bcc) metals and alloys have attracted much attention in the past decade due to their reduced-activation under irradiation environment [14-18]. The studies on the oxide-dispersion strengthened (ODS) ferrite steels [19-22] have showed great radiation tolerance since dispersed nanoparticles in the matrix increase the volume fraction of the interfaces which can act as sinks for irradiation-induced defects, especially for He bubbles.

Similarly, nanocrystalline (NC) materials exhibit great potential for such applications because a large fraction of grain and interphase boundaries can act as effective sinks for irradiation-induced vacancies and bubbles $[2,6,23,24]$. Refining the grains of materials into nanometer size can significantly alter the physical, chemical and mechanical behaviors of the materials [25-31]. Previous reports [32-35] on fcc/bcc nanolayered composites have showed extreme tolerance to He bubbles, which are prone to segregate at interphase boundaries. Bulk NC metals have also displayed extraordinary radiation 
healing behavior due to grain boundary (GB) accommodation of defects [36-38].

Although there are many reports about the radiation damage on NC metals and alloys, it remains elusive about how the change of grain size affects the radiation tolerance. To explore this issue, here we investigate the effect of grain size on the mechanical properties and the microstructure evolution of $\mathrm{NC}$ bcc metals before and after He ion irradiation, using Mo as a model material.

Mo films with thickness of at least $1.5 \mu \mathrm{m}$ were synthesized on silicon (100) substrates using magnetron sputtering. The deposition rate was varied in order to control the average grain size. Mo films with average grain sizes ranging from 25 to $455 \mathrm{~nm}$ and coarse-grained (CG) Mo foil (listed in Table 1) were irradiated together at room temperature, using $200 \mathrm{keV} \mathrm{He}$ ions with a total fluence of $1.4 \times 10^{17} \mathrm{ions} / \mathrm{cm}^{2}$. The peak damage was $\sim 4$ dpa (displacement per atom) and the He concentration $\sim 1.9 \%$ (see details in the supplementary materials). The indentation hardness and modulus of Mo samples before and after He ion irradiation were measured based on an average value of at least 9 indents at each load from HYSITRON TI900 TriboIndenter with a Berkovich tip (tip diameter, $45 \mathrm{~nm}$ ). The maximum indentation depth was $150 \mathrm{~nm}$ for all thin film specimens and $250 \mathrm{~nm}$ for bulk specimen. Microstructures of Mo samples before and after irradiation were examined by X-ray diffraction, scanning electron microscopy (SEM) and transmission electron microscopy (TEM). Both plane-view (peeling off) and crosssection (wedge-shaped) samples were ion-milled at $-70^{\circ} \mathrm{C}$, with low energy $(3.5 \mathrm{keV})$ and low angle $\left(<4^{\circ}\right)$. TEM and high-resolution TEM (HRTEM) observations were carried out using a JEOL 2010F microscope operating at $200 \mathrm{kV}$.

Series of Mo films with different average grain size were prepared, and the grain size 
distribution was uniform based on both plane-view and cross-sectional TEM observations. Figure 1 shows the morphologies of one of the typical NC Mo films. The thickness of the Mo film was measured to be $1.5 \mu \mathrm{m}$ from the cross-sectional view in Fig. 1d obtained by SEM. From the plane-view bright-field and dark-field TEM images in Figs. $1 \mathrm{~b}$ and $\mathrm{c}$, the distribution of the grain size is uniform (see the plot in the inset of Fig. 1b), and the average grain size is $44 \mathrm{~nm}$, taken 500 grains into account. The average grain size along the growth direction is $100 \mathrm{~nm}$, as shown in Figs. 1e and $\mathrm{f}$.

The hardness deviation of bcc Mo samples before and after He ion irradiation is presented in Fig. 2a as a function of the grain size, where the grain size is the average value of each Mo sample (Table 1). The reduction of grain size introduces strong hardening in NC Mo thin films before He ion irradiation (marked by open square in Fig. 2a), which is similar to the previous report [30]. The hardness of Mo samples after irradiation continuously increases with decreasing the grain size. And the hardness values of irradiated Mo samples (marked by open circle in Fig. 2a) are larger than those of their unirradiated counterparts. It indicates that there is additional irradiation-induced hardening due to the irradiation-induced defects, besides of the hardening from the reduction of grain size. Note that there is no obvious change of grain size or residue stress of the Mo samples before and after He ion irradiation based on the XRD analysis. It can be seen from Fig. 2a that dramatic irradiation-induced hardening is in the irradiated samples with grain size of $>90 \mathrm{~nm}$. Especially in CG Mo, the hardness of irradiated sample is increased by $4.5 \mathrm{GPa}$ and reaches to $7.2 \mathrm{GPa}$, which means that a high density of defects is induced into the sample during He ion irradiation. However, the hardness increment $\left(\Delta \mathrm{H}_{\text {ir }}=\mathrm{H}_{\text {irradiated }}-\mathrm{H}_{\text {unirradiated }}\right)$ before and after irradiation decreases as the grain 
size decreases, shown in Fig. 2c (the hardness increment as a function of the grain size).

The hardness increment has a dramatic decrease when the grain size is less than $90 \mathrm{~nm}$, and is close to zero in NC Mo with a grain size of $25 \mathrm{~nm}$. This is probably due to a remarkable reduction of irradiation-induced defects in them. Accordingly, the irradiationinduced hardening can be effectively reduced by decreasing the grain size.

Figures 3 and 4 show the dominant irradiation-induced defects (He bubbles and dislocation loops) in irradiated NC and CG Mo with grain sizes of $44 \mathrm{~nm}$ (Mo5) and 3.9 $\mu \mathrm{m}(\mathrm{Mo} 0)$, respectively. It is clearly seen in Figs. 3a and $\mathrm{c}$ that both have a very high density of He bubbles, which is of the order of $10^{23}-10^{24} \mathrm{~m}^{-3}$ (the number of bubbles per unit volume), but the distribution of He bubbles is different as the grain size changes. The He bubbles tend to segregate to the GBs in irradiated NC Mo (Fig. 3a). Note that the two TEM images are under the same imaging conditions. The density of He bubbles in irradiated NC Mo is less than that in irradiated CG Mo based on the statistic data in Fig. $2 \mathrm{~b}$, and the average diameter of He bubbles in irradiated NC Mo (Mo5) is $0.6 \mathrm{~nm}$, which is only half of that in irradiated CG Mo (Mo0) with a value of $1.2 \mathrm{~nm}$, shown in Figs. $3 \mathrm{~b}$ and d.

Furthermore, there is a high density of dislocation loops in irradiated CG Mo $\left(\sim 10^{24} \mathrm{~m}^{-}\right.$ ${ }^{3}$, the number of loops per unit volume), but less dislocation loops $\left(10^{22} \mathrm{~m}^{-3}\right)$ in irradiated NC Mo, shown in Fig. 2d. Figure 4 shows TEM and HRTEM images of the irradiationinduced dislocation loops in $\mathrm{NC}$ (Mo5) and CG (Mo0) Mo after He ion irradiation. Details of loop characterization (type, Burgers vector, etc.) in irradiated bcc bulk metals can be referred to Refs [39-41]. The irradiation-induced dislocation loops show clear image contrast in irradiated CG Mo (Fig. 4c) but not in irradiated NC Mo (Fig. 4a). A 
magnified TEM image of the dislocation loops in irradiated CG Mo is shown in the inset in Fig. 4c. And the edge-on interstitial loops in irradiated NC and CG Mo are marked in the HRTEM images in Figs. $4 \mathrm{~b}$ (the inset) and d, respectively. Note that there is much less dislocation loops $\left(<10^{20} \mathrm{~m}^{-3}\right)$ in all unirradiated Mo samples (see Fig. S3 in the supplementary materials). Moreover, HRTEM investigation also revealed that there was a high density of dislocations with edge component in both irradiated NC and CG Mo (almost the same order of magnitude, $\sim 10^{15} \mathrm{~m}^{-2}$, the number of dislocations per unit area), shown in Figs. $4 \mathrm{~b}$ and d. The observed dislocations in NC Mo were mainly from the edge or mixed dislocations $[29,42]$ and their density was almost at the same order of magnitude in both irradiated and unirradiated samples. But most of them in irradiated CG Mo might be from the projection of dislocation loops since no obvious dislocation line was observed via two-beam imaging. Accordingly, irradiation-induced bubbles and dislocation loops may significantly contribute to the obvious irradiation-induced hardening phenomena in irradiated Mo samples with different grain size. In the following we will discuss the possible hardening mechanism from the irradiation-induced defects (He bubbles and dislocation loops) based on the statistical data in Figs. $2 \mathrm{~b}$ and d.

As we know, irradiation-induced hardening is mainly related to the induced defects such as point defects, clusters, dislocations, loops and He bubbles. Here, the hardening effect can be divided into two parts.[12]. One is from He bubbles, and the other is from dislocation loops, etc. For He bubble induced hardening, a hardening relationship developed by Friedel-Kroupa-Hirsch (FKH) $[43,44]$ can be used to describe the irradiation-induced increase in yield strength, $\Delta \sigma_{\text {bubble }}$.

$$
\Delta \sigma_{\text {bubble }}=\frac{1}{8} M G b d N_{H e}^{2 / 3}
$$


where $\mathrm{M}$ is Taylor factor, 3.05 for bcc metal; $\mathrm{G}$ is the shear modulus (GPa), $\sim 128 \mathrm{GPa}$ from the nanoindentation data; $b$ is the Burgers vector $(\mathrm{nm}), 1 / 2<111>$ used here; $d$ is the bubble diameter $(\mathrm{nm})$ and $\mathrm{N}$ the bubble density $\left(\mathrm{m}^{-3}\right)$. The increase in yield stress from FKH model corresponds to a hardness increase $\left(\Delta \mathrm{H}_{\text {bubble }} \approx 3 \Delta \sigma_{\text {bubble }}\right)$ in Fig. $2 \mathrm{c}$. As shown, the hardening from He bubbles (marked by down triangle in Fig. 2c) is slightly decreased as the grain size decreases, but is much smaller than the total hardness increment (marked by solid diamond in Fig. 2c).

To compare with the hardening from He bubbles, the hardening from irradiationinduced dislocation loops is taken into account. Based on a dispersed barrier hardening model [12], the increase in yield stress is equal to the increase in applied stress required to move a dislocation through a field of obstacles:

$$
\Delta \sigma_{y}=\alpha M G b(N d)^{1 / 2}
$$

where $\alpha$ is the barrier strength, 0.1 for loops; $\mathrm{N}$ is the loop density $\left(\mathrm{m}^{-3}\right)$ and $\mathrm{d}$ the loop diameter (nm). The density and diameter of small loops can be estimated from TEM and HRTEM images, as shown Fig. 2d. Take irradiated NC Mo5 and CG Mo0 as examples, the average loop densities are $1.5 \times 10^{22} \mathrm{~m}^{-3}$ and $1.9 \times 10^{24} \mathrm{~m}^{-3}$, and the average loop diameters are $2.0 \mathrm{~nm}$ and $5.8 \mathrm{~nm}$, respectively. Thus, we can calculate the yield stress from equation (2) and obtain the hardness of $0.17 \mathrm{GPa}$ and $3.37 \mathrm{GPa}$ for irradiated NC Mo5 and CG Mo0, respectively. The hardness from both bubbles and loops for irradiated NC Mo5 and CG Mo0 are 0.38 and $3.98 \mathrm{GPa}$, respectively. Both are very close to the measured hardness increment $(0.4$ and $4.5 \mathrm{GPa})$ in Fig. 2c. It indicates that the additional hardening effect in irradiated Mo samples is mainly from the irradiation-induced dislocation loops and He bubbles. 
As shown in Fig. 2c, the strong irradiation-induced hardening effect in ultra-finegrained (UFG) or CG Mo (grain size $>90 \mathrm{~nm}$ ) is mainly from the irradiation-induced dislocation loops. But as the grain size decreases into $90 \mathrm{~nm}$, the irradiation-induced hardening decreases dramatically because both the density and the size of dislocation loops and He bubbles decreases, especially the dramatic reduction of the density of the irradiation-induced dislocation loops. It should be noted that healing mechanism [37] may work in NC bcc metals under irradiation since interstitials released from GBs will help to annihilate the irradiation-induced defects such as vacancies and even decrease the density and the size of dislocation loops. And amounts of GBs in NC bcc metals can effectively act as sinks for He bubbles to reduce the negative effect of them [35]. Hence, the radiation tolerance of $\mathrm{NC} \mathrm{bcc} \mathrm{metals} \mathrm{will} \mathrm{be} \mathrm{well} \mathrm{improved} \mathrm{as} \mathrm{the} \mathrm{grain} \mathrm{size} \mathrm{decreases.}$

In summary, NC Mo shows much greater radiation resistance when the grain size is less than $90 \mathrm{~nm}$ than their UFG or CG counterparts. With decreasing grain size, the hardness increment of NC Mo after irradiation decreases and even reaches to zero at the grain size of $25 \mathrm{~nm}$. This is because a low density and a small size of defects (dislocation loops and He bubbles) are produced in the grains smaller than $90 \mathrm{~nm}$ during irradiation.

\section{Acknowledgement}

This work was supported by the Laboratory Directed Research and Development program office of the Idaho National Laboratory. He ion implantation was supported by Center for Integrated Nanotechnologies, a DOE nanoscience user facility jointly operated by Los Alamos and Sandia National Laboratories. The authors wish to thank Dr. Dieter Wolf whose insight and discussions with the authors inspired and initiated the current study on bcc metals. The authors acknowledge the use of the Analytical Instrumentation 
Facility (AIF) at North Carolina State University, which is supported by the State of North Carolina and the National Science Foundation. 
[1] Ackland G, Controlling Radiation Damage, Science 327, 1587-88 (2010).

[2] Grimes RW, Konings RJM and Edwards L, Greater tolerance for nuclear materials, Nat. Mater. 7, 683-85 (2008).

[3] DOE US, A Technology Roadmap for Generation IV Nuclear Energy Systems Nuclear Energy Advisory Committee and the Generation IV International Forum, GIF002-00 (2002).

[4] Grimes RW and Nuttall WJ, Generating the Option of a Two-Stage Nuclear Renaissance, Science 329, 799-803 (2010).

[5] Allen T, Busby J, Meyer M and Petti D, Materials challenges for nuclear systems, Materials Today 13, 14-23 (2010).

[6] Bringa EM, Monk JD, Caro A, Misra A, Zepeda-Ruiz L, Duchaineau M, Abraham F, Nastasi M, Picraux ST, Wang YQ and Farkas D, Are Nanoporous Materials Radiation Resistant?, Nano Lett. 12, 3351-55 (2012).

[7] Xu W, Zhang Y, Cheng G, Jian W, Millett PC, Koch CC, Mathaudhu SN and Zhu Y, In-situ atomic-scale observation of irradiation-induced void formation, Nature Communications 4 (2013).

[8] Farnan I, Cho H and Weber WJ, Quantification of actinide [agr]-radiation damage in minerals and ceramics, Nature 445, 190-93 (2007).

[9] Novikov LS, Mileev VN, Voronina EN, Galanina LI, Makletsov AA and Sinolits VV, Radiation effects on spacecraft materials, Journal of Surface Investigation-X-Ray Synchrotron and Neutron Techniques 3, 199-214 (2009).

[10] Xu WZ, Zhang YF, Cheng GM, Jian WW, Millett PC, Koch CC, Mathaudhu SN and Zhu YT, Dynamic Void Growth and Shrinkage in $\mathrm{Mg}$ under Electron Irradiation, Materials Research Letters 2, 176-83 (2014).

[11] Cheng G, Yao S, Sang X, Hao B, Zhang D, Yap YK and Zhu Y, Evolution of Irradiation-Induced Vacancy Defects in Boron Nitride Nanotubes, Small 12, 818-24 (2016).

[12] Was GS, Fundamentals of Radiation Materials: Metals and Alloys, (Springer, 2007).

[13] Wirth BD, How does radiation damage materials?, Science 318, 923-24 (2007).

[14] Baluc N, Gelles DS, Jitsukawa S, Kimura A, Klueh RL, Odette GR, van der Schaaf $\mathrm{B}$ and $\mathrm{Yu}$ J, Status of reduced activation ferritic/martensitic steel development, J. Nucl. Mater. 367, 33-41 (2007).

[15] Baluc N, Abe K, Boutard JL, Chernov VM, Diegele E, Jitsukawa S, Kimura A, Klueh RL, Kohyama A, Kurtz RJ, Lasser R, Matsui H, Moslang A, Muroga T, Odette GR, Tran MQ, Van der Schaaf B, Wu Y, Yu I and Zinkle SJ, Status of R\&D activities on materials for fusion power reactors, Nuclear Fusion 47, S696-S717 (2007).

[16] Zarkadoula E, Daraszewicz SL, Duffy DM, Seaton MA, Todorov IT, Nordlund K, Dove MT and Trachenko K, The nature of high-energy radiation damage in iron, Journal of Physics: Condensed Matter 25, 125402 (2013).

[17] Tan X, Luo L, Chen H, Zhu X, Zan X, Luo G, Chen J, Li P, Cheng J, Liu D and Wu $\mathrm{Y}$, Mechanical properties and microstructural change of $\mathrm{W}-\mathrm{Y}(2) \mathrm{O}(3)$ alloy under helium irradiation, Scientific Reports 5, 12755 (2015).

[18] Beeler B, Asta M, Hosemann P and Grønbech-Jensen N, Effect of strain and temperature on the threshold displacement energy in body-centered cubic iron, J. Nucl. Mater. 474, 113-19 (2016).

[19] Allen TR, Gan J, Cole JI, Miller MK, Busby JT, Shutthanandan S and Thevuthasan S, 
Radiation response of a 9 chromium oxide dispersion strengthened steel to heavy ion irradiation, J. Nucl. Mater. 375, 26-37 (2008).

[20] Odette GR and Hoelzer DT, Irradiation-tolerant Nanostructured Ferritic Alloys: Transforming Helium from a Liability to an Asset, Jom 62, 84-92 (2010).

[21] Zinkle SJ and Ghoniem NM, Operating temperature windows for fusion reactor structural materials, Fusion Engineering and Design 51-52, 55-71 (2000).

[22] Ukai S and Fujiwara M, Perspective of ODS alloys application in nuclear environments, J. Nucl. Mater. 307, 749-57 (2002).

[23] Xu W, Li L, Saber M, Koch CC, Zhu Y and Scattergood RO, Observation of nanosize $\mathrm{ZrO} 2$ in nanocrystalline Fe-14Cr-1.5Zr alloy, J. Nucl. Mater. 452, 434-39 (2014).

[24] Yu KY, Liu Y, Sun C, Wang H, Shao L, Fu EG and Zhang X, Radiation damage in helium ion irradiated nanocrystalline Fe, J. Nucl. Mater. 425, 140-46 (2012).

[25] Zhu YT, Liao XZ and Wu XL, Deformation twinning in nanocrystalline materials, Progress in Materials Science 57, 1-62 (2012).

[26] Meyers MA, Mishra A and Benson DJ, Mechanical properties of nanocrystalline materials, Progress in Materials Science 51, 427-556 (2006).

[27] Zhao YH, Topping T, Bingert JF, Thornton JJ, Dangelewicz AM, Li Y, Liu W, Zhu YT, Zhou YZ and Lavernia EL, High tensile ductility and strength in bulk nanostructured nickel, Adv. Mater. 20, 3028-33 (2008).

[28] Wu XL, Zhu YT, Wei YG and Wei Q, Strong Strain Hardening in Nanocrystalline Nickel, Phys. Rev. Lett. 103 (2009).

[29] Cheng GM, Jian WW, Xu WZ, Yuan H, Millett PC and Zhu YT, Grain Size Effect on Deformation Mechanisms of Nanocrystalline bcc Metals, Materials Research Letters 1, 26-31 (2013).

[30] Zhou Q, Zhao J, Xie JY, Wang F, Huang P, Lu TJ and Xu KW, Grain size dependent strain rate sensitivity in nanocrystalline body-centered cubic metal thin films, Materials Science and Engineering: A 608, 184-89 (2014).

[31] Cheng GM, Yuan H, Jian WW, Xu WZ, Millett PC and Zhu YT, Deformationinduced $\omega$ phase in nanocrystalline Mo, Scr. Mater. 68, 130-33 (2013).

[32] Wei QM, Li N, Mara N, Nastasi M and Misra A, Suppression of irradiation hardening in nanoscale V/Ag multilayers, Acta Mater. 59, 6331-40 (2011).

[33] Li N, Fu EG, Wang H, Carter JJ, Shao L, Maloy SA, Misra A and Zhang X, He ion irradiation damage in Fe/W nanolayer films, J. Nucl. Mater. 389, 233-38 (2009).

[34] Misra A, Hirth JP and Hoagland RG, Length-scale-dependent deformation mechanisms in incoherent metallic multilayered composites, Acta Mater. 53, 4817-24 (2005).

[35] Misra A, Demkowicz MJ, Zhang X and Hoagland RG, The radiation damage tolerance of ultra-high strength nanolayered composites, Jom 59, 62-65 (2007).

[36] Samaras M, Derlet PM, Van Swygenhoven H and Victoria M, Computer simulation of displacement cascades in nanocrystalline Ni, Phys. Rev. Lett. 88 (2002).

[37] Bai X-M, Voter AF, Hoagland RG, Nastasi M and Uberuaga BP, Efficient Annealing of Radiation Damage Near Grain Boundaries via Interstitial Emission, Science 327, 1631-34 (2010).

[38] Zhang Y, Millett PC, Tonks M, Zhang L and Biner B, Molecular dynamics simulations of He bubble nucleation at grain boundaries, J. Phys.-Condes. Matter 24 (2012). 
[39] Eyre BL, Maher DM and Perrin RC, ELECTRON-MICROSCOPE IMAGECONTRAST FROM SMALL DISLOCATION LOOPS .1. THEORETICAL PREDICTIONS FOR EDGE DISLOCATION LOOPS IN A BCC CRYSTAL, Journal of Physics F-Metal Physics 7, 1359-69 (1977).

[40] English CA, Eyre BL and Holmes SM, ELECTRON-MICROSCOPE IMAGECONTRAST FROM SMALL DISLOCATION LOOPS .4. APPLICATION OF THEORETICAL PREDICTIONS FOR NON-EDGE LOOPS TO DEFECT ANALYSIS IN IRRADIATED MOLYBDENUM, Journal of Physics F-Metal Physics 10, 1065-80 (1980).

[41] Maher DM and Eyre BL, The identification of vacancy and interstitial loops in neutron irradiated molybdenum, Philos. Mag. 17, 1-6 (1968).

[42] Cheng GM, Xu WZ, Jian WW, Yuan H, Tsai MH, Zhu YT, Zhang YF and Millett PC, Dislocations with edge components in nanocrystalline bcc Mo, Journal of Materials Research 28, 1820-26 (2013).

[43] Friedel J, On the linear work hardening rate of face-centred cubic single crystals, Philos. Mag. 46, 1169-86 (1955).

[44] Kroupa F and Hirsch PB, Elastic interaction between prismatic dislocation loops and straight dislocations, Discussions of the Faraday Society 38, 49-55 (1964). 


\section{Table captions}

Tab. 1. Average grain size corresponding to the different samples from Mo thin films prepared by magnetron sputtering and as-received Mo foil. 


\section{Figure Captions}

Fig. 1 SEM (a, d), bright-field TEM (b, e) and dark-field TEM (c, f) images of typical NC Mo film prepared by magnetron sputtering. (a-c) from plane-view; (d-f) from crosssectional view. The inset in (b) shows the distribution of grain size based on 500 grains. The average grain size is $44 \mathrm{~nm}$. The inset in (c) is the corresponding SAED pattern.

Fig. 2 Grain size effect on the hardening behavior of bcc Mo before and after He ion irradiation. (a) Hardness deviation of bcc Mo samples before and after irradiation; (c) Hardness increment after irradiation. (b, d) Distribution of size and density of irradiation-induced He bubbles and dislocation loops in bcc Mo samples after irradiation, respectively.

Fig. 3 TEM investigation of irradiation-induced He bubbles in NC Mo5 (a) and CG Mo0 (c) after He ion irradiation. (b, d) Bubble size distribution in NC Mo5 and CG Mo0 after irradiation, respectively.

Fig. 4 TEM and HRTEM investigation of irradiation-induced defects (loops and dislocations) in NC Mo5 (a-b) and CG Mo0 (c-d) after He ion irradiation. Loops and mixed dislocations are marked in (d) and the inset in (b). 
Tab. 1 Average grain size (from plane-view) corresponding to the different samples from Mo thin films prepared by magnetron sputtering and as-received Mo foil.

\begin{tabular}{cc}
\hline Sample type & Average grain size $(\mathrm{nm})$ \\
\hline Mo6 & 25 \\
Mo5 & 44 \\
Mo4 & 68 \\
Mo3 & 90 \\
Mo2 & 185 \\
Mo1 & 455 \\
Mo0 & 3900 \\
\hline
\end{tabular}




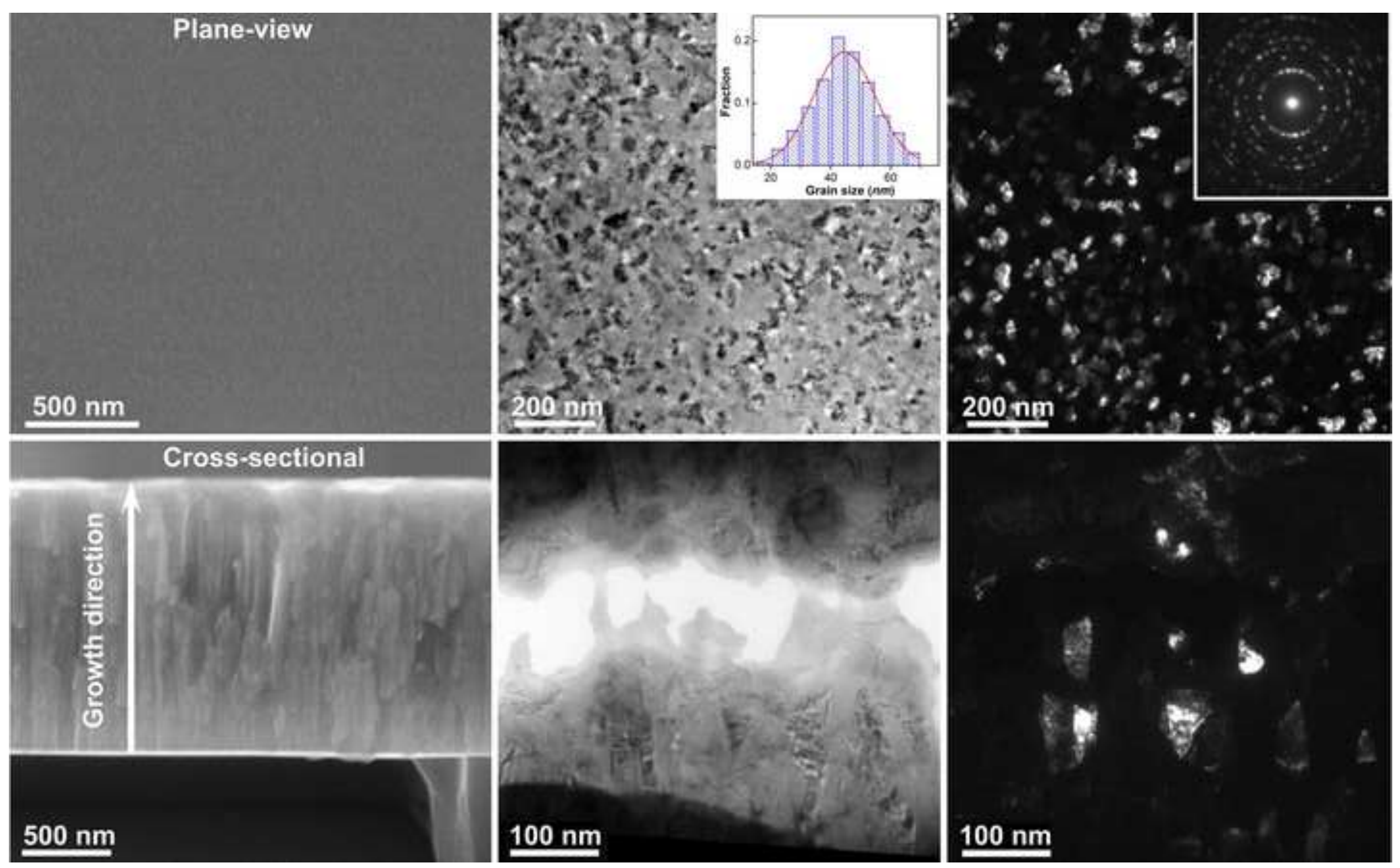



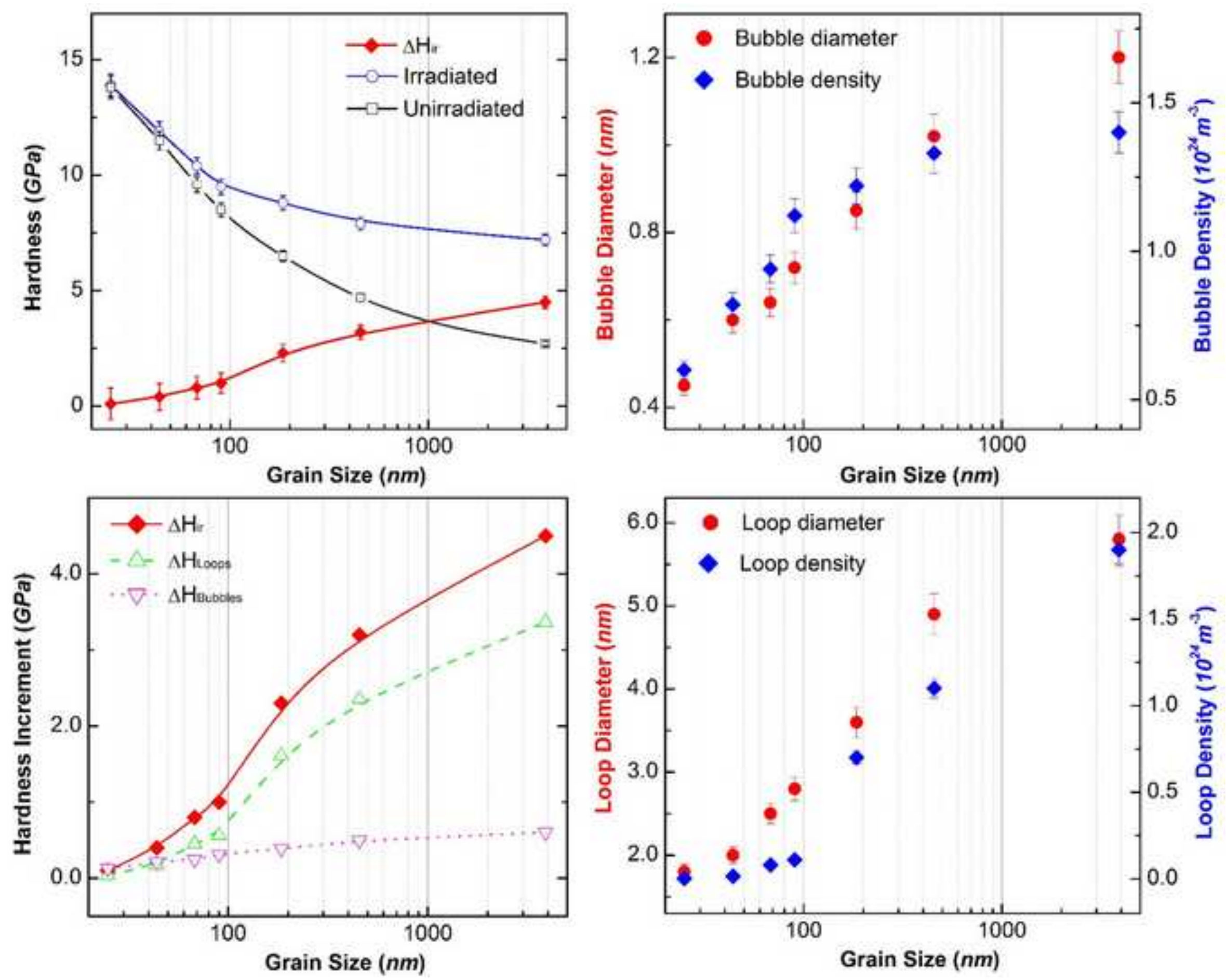

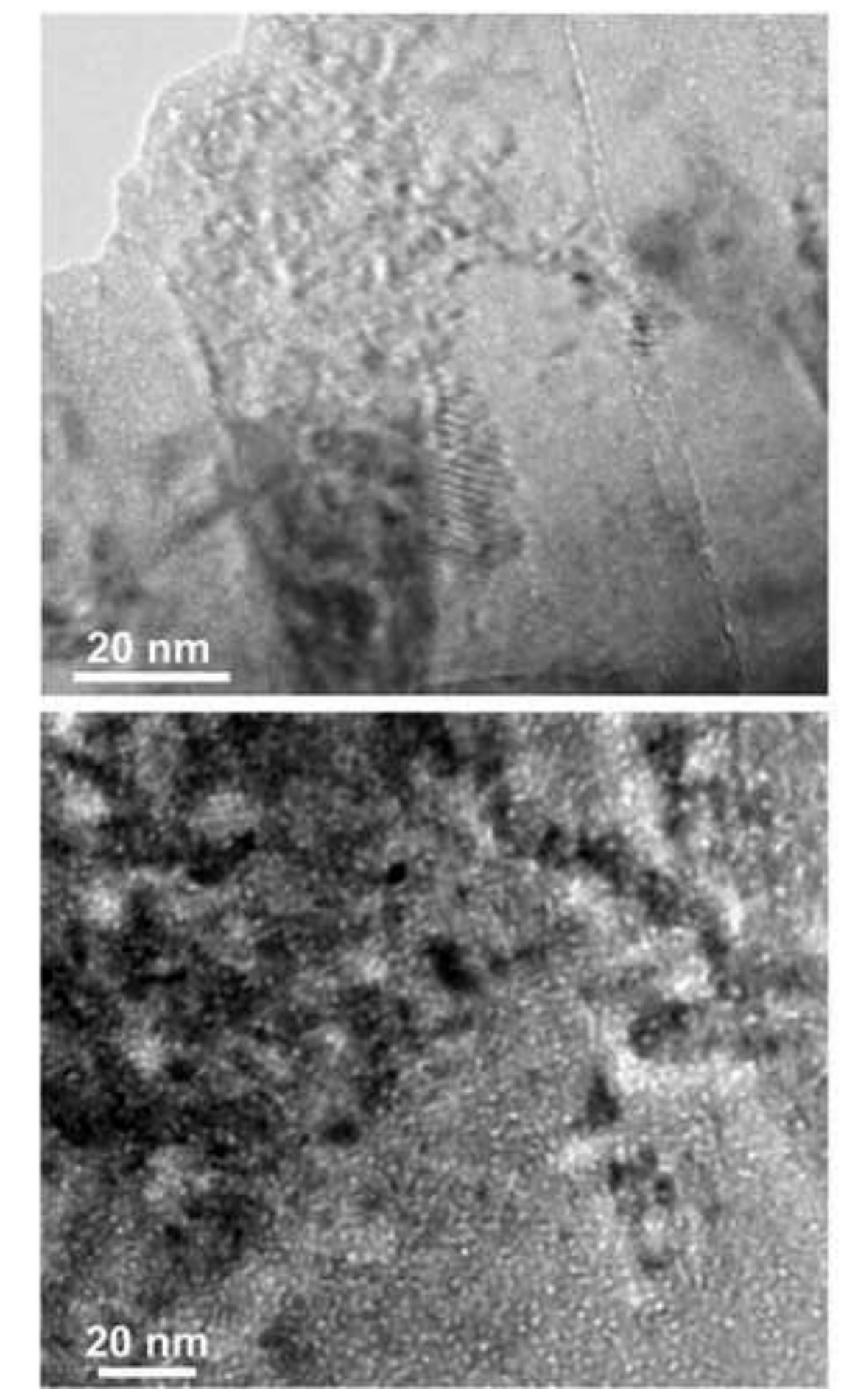
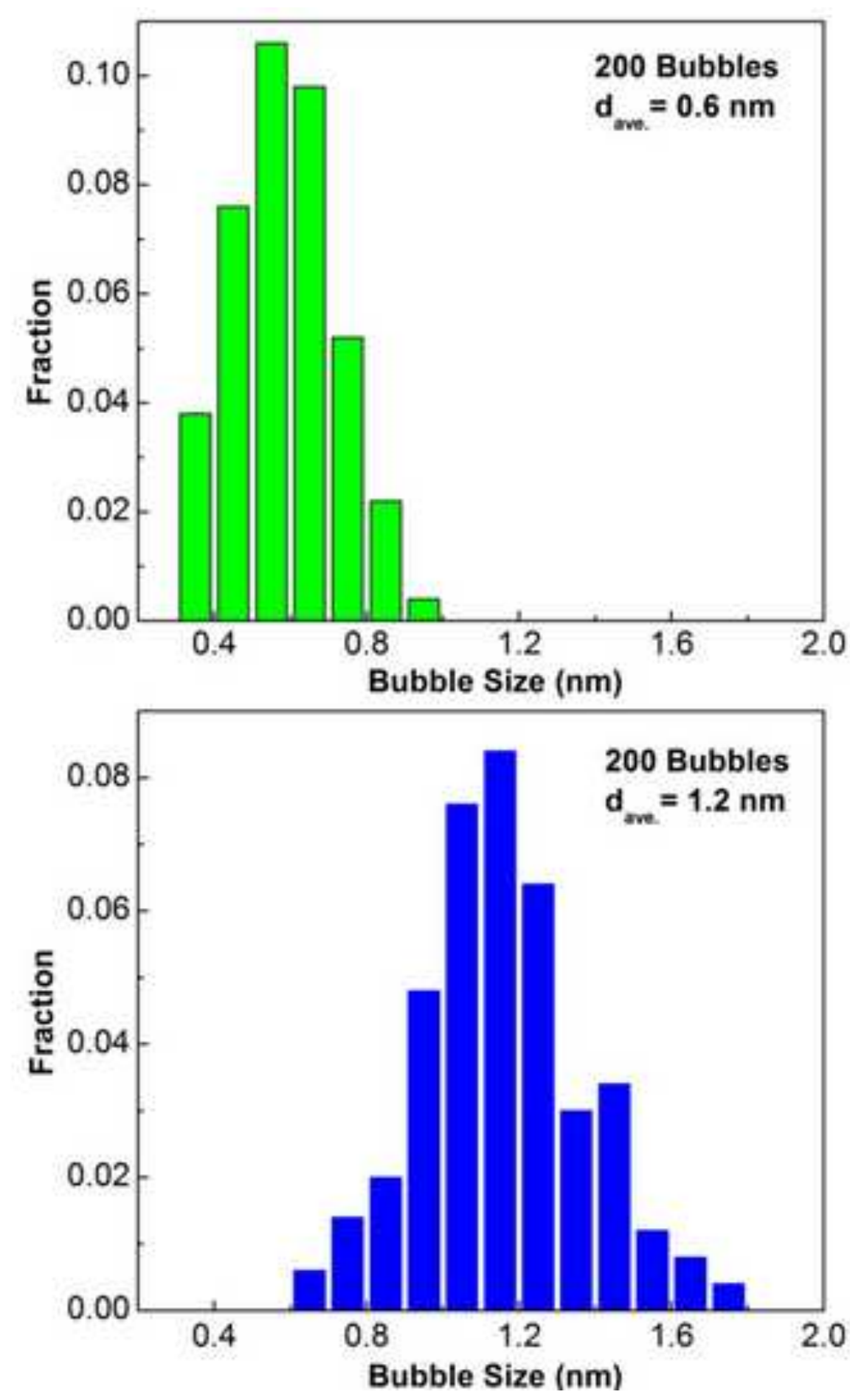


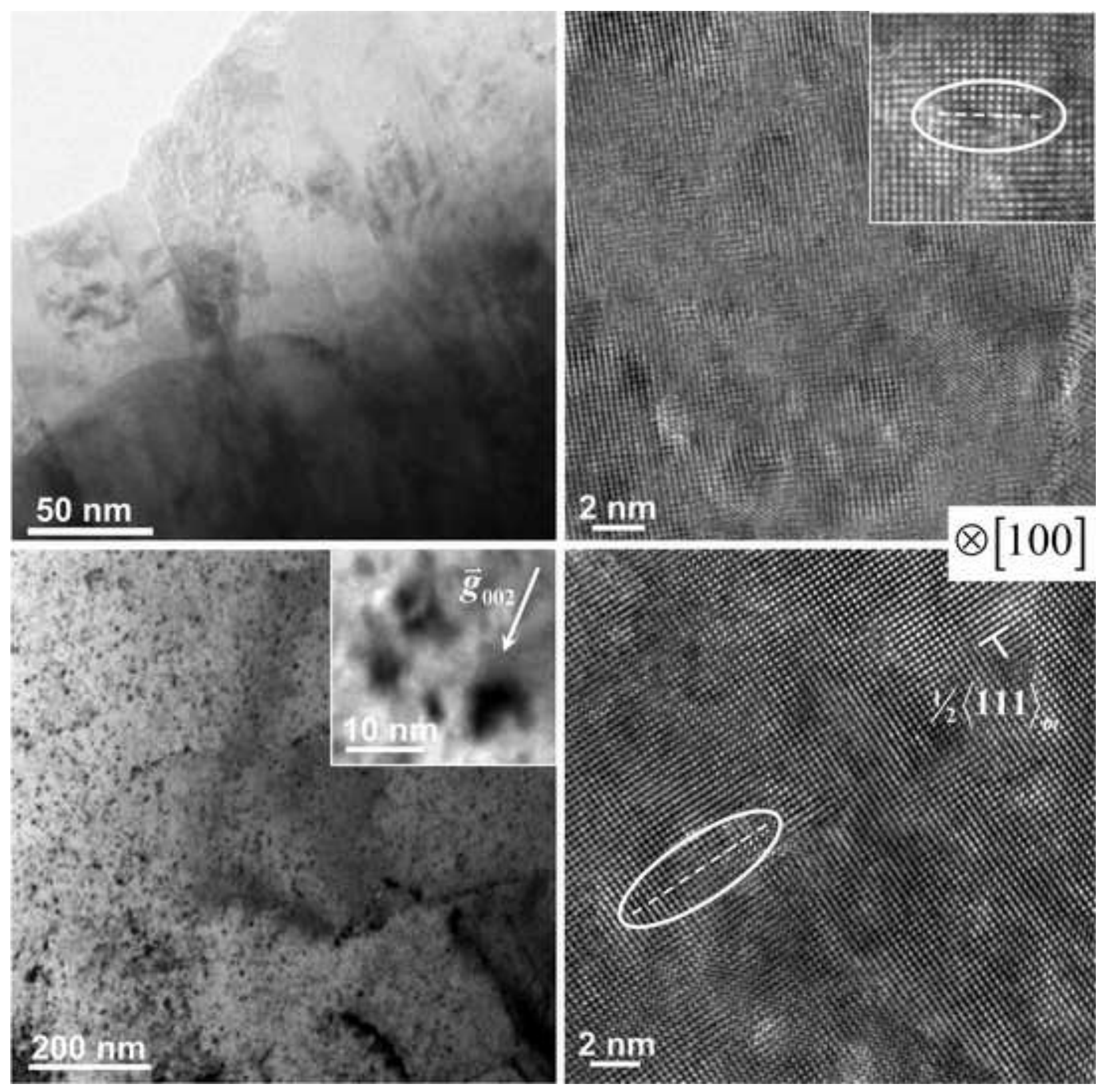

